\title{
Ability to initiate relationships and sense of loneliness mediate the relationship between low self-esteem and excessive internet use
}

\author{
Aleksandra Dembińska ${ }^{1}$ (D) Joanna Kłosowska ${ }^{2}$ (D) $\cdot$ Dominika Ochnik $^{3}$ (D)
}

Accepted: 15 October 2020 / Published online: 4 November 2020

(C) The Author(s) 2020

\begin{abstract}
The purpose of the study was to identify possible mechanisms underlying the relationship between low self-esteem and excessive Internet use in a non-clinical sample of young adults. Basing on the theoretical framework and results of existing studies we hypothesized that the association between self-esteem and excessive Internet use will be serially mediated by the ability to initiate contact with others and sense of loneliness. The study sample consisted of 506 participants (60\% women) aged between 18 and 35 years $($ mean $=19)$. The following questionnaires were administered: the Rosenberg Self-Esteem Scale, the UCLA Loneliness Scale, the Interpersonal Competence Questionnaire and the Excessive Internet Use Scale. The last measure was prepared by authors for the purpose of the study. Serial mediation analysis was conducted. In line with our hypotheses the link between low self-esteem and excessive Internet use was found to be sequentially mediated by the capability to initiate social contacts and chronic loneliness. Difficulty in engaging in social interaction leading to the sense of loneliness may explain the link between low self-esteem and excessive Internet use. These results may help to design early intervention programs.
\end{abstract}

Keywords Self-esteem $\cdot$ Loneliness $\cdot$ Interpersonal competence $\cdot$ Excessive internet use $\cdot$ Serial mediation model

\section{Introduction}

Since the mid-1990s there has been an ongoing debate on the phenomenon of Internet addiction, triggered inadvertently by Goldberg (1996). The Internet Addiction Disorder (IAD)is a complex and heterogeneous phenomenon characterised by the inner urge to be online. According to Goldberg Pathological Computer/ Internet Use Disorder is a term suggested to describe the situation when people use the Internet in excess which leads to distress and impacts their physical, interpersonal, social, family and economic functioning. Kimberly Young (1996), a pioneer of research on this phenomenon listed the following symptoms of Internet addiction:

- $\quad$ preoccupation with the Internet;

Aleksandra Dembińska

Aleksandra@dembinska.pl

1 Department of Psychology, Pedagogical University of Cracow, Krakow, Poland

2 Institute of Psychology, Jagiellonian University, Krakow, Poland

3 Faculty of Medical Sciences, University of Technology in Katowice, Katowice, Poland
- $\quad$ need to spend more time online;

- $\quad$ trying to reduce Internet use;

- symptoms of withdrawal after reducing the duration/ intensity of Internet use;

- time management issues (following excessive use of the Internet);

- issues with the social circles (family, school, work, friends);

- underestimating time spent in the Internet;

- mood modification following Internet use.

Some authors postulate that Internet addiction should be differentiated from excessive Internet use (Pontes, Kuss, \& Griffiths, 2015). Excessive users usually do not meet all the criteria of addiction and are not characterized by such severe impairments as addicted users (Griffiths, 2005). However, over time, excessive Internet use may result in the development of Internet addiction (Kim \& Haridakis, 2009). Therefore, it seems particularly important to identify risk factors associated with excessive Internet use as they may help us better understand the process of developing addiction.

It is suggested that excessive Internet use as well as IAD can stem from the Internet itself - its multifunctionality - or the person using the Internet. Among individual sensitivity factors researchers point out to the role of self-esteem 
(Stieger \& Burger, 2010; Wartberg et al., 2011; Dembinska \& Ochnik, 2014; Younes et al., 2016; Niemz et al., 2005; Kim \& Davis, 2009). It has been suggested that individuals with low self-esteem tend to engage in addictive behaviours in order to withdraw or escape from negative evaluations of themselves (e.g., Craig, 1995). Low self-esteem was identified in many previous studies as a significant positive predictor of addictive Internet use (e.g. Armstrong, Phillips, \& Saling, 2000; Kim \& Haridakis, 2009; Widyanto \& Griffiths, 2019).

So far there have been a few hypotheses formulated to explain the possible pathways linking low self-esteem with excessive Internet use.The first one may lead through perceived lack of social skills and difficulties in initiating contacts with others. Numerous studies (Aouil and Siedlaczek, 2011; Casale and Fioravanti, 2011; Kormas et al. 2011; Kittinger, 2012; Fioravanti et al. 2012; Durkee et al. 2012; Smahel et al., 2012; Dembińska and Ochnik, 2014; Young, 1998) showed that people who use Internet excessively, more frequently than others use services offering interaction with other Internet users (chat rooms, on-line games, discussion groups, email). Caplan (2003) suggests that individuals with low self-esteem perceive themselves as incompetent in social communication. They prefer online communication, which makes them feel less stressed and more in control of how they present themselves. Similarly, Griffiths (2000) concludes that using the Internet by the individuals is closely related to their perception of online communication as a way of compensating low self-esteem by assuming a different social identity. Lee and Cheung (2014) also point out that low self-esteem predisposes individuals to develop a preference for online social interaction. In particular people who lack social skills seem to prefer social interaction online to direct communication (Caplan, 2006). This preference encourages excessive Internet use leading to negative consequences.

The sense of loneliness seems to be another important factor linking low self-esteem and difficulties in initiating contacts with others to excessive Internet use. Studies (e.g., Riggio and De Paola, 1990) indicate thatpoor self-esteem and low social skills are related to higher level of loneliness. For example, Solano and Koester (1989) observed that both weak social competences and anxiety regarding these competences are independently linked with increased loneliness (see Panayiotou, Pantelia, \& Theodorou, 2016). Similarly, Zhao, Kong, and Wang (2012) reported that individuals with negative self-esteem, presenting lack of confidence in their social behaviour begin to experience the sense of loneliness. It has been postulated that lonely individuals may use technology to replace real world contacts with online interaction- preferring to interact with others via the Internet rather than directly (Nowland, Necka, \& Cacioppo, 2018). According to McKenna and Bargh (2000), people who experience loneliness because of their lack of social skills try to overcome their difficulties through online social interactions. Such interactions seem less dangerous and therefore more attractive
(Davis, 2001; Coplan and Bowker, 2014; Yao and Zhong, 2014).Unfortunately, using Internet repeatedly to alleviate loneliness may lead to excessive Internet use or development of dependence (Caplan, 2002).

Despite the fact, that several suggestions to explain the link between low self-esteem and excessive Internet use have been formulated, there have been few studies conducted to verify these theories. The objective of this study is, therefore, to fill this gap by testing a hypothetical model explaining the mechanism underlying the link between self-esteem and excessive Internet use. Basing on the existing literature and the results of previous studies the following hypotheses were formulated:

1. There is a significant, negative relationship between selfesteem and excessive Internet use.

2. The link between self-esteem and excessive Internet use is mediated by the lack of ability to initiate contact with others.

3. The association between low self-esteem and excessive Internet use is mediated by the sense of loneliness.

4. There is a serial mediational relationship between low self-esteem and excessive Internet use through lack of ability to initiate contacts and feeling of loneliness. In particular, low self-esteem is significantly associated with the inability to initialize social contact which is significantly related to the sense of loneliness which in turn significantly correlates with excessive Internet use.

\section{Methods}

\section{Participants}

The convenient sample consisted of 506 participants $(60 \%$ females) aged between 18 and 35 years $(M=19.89, \mathrm{SD}=$ 1.32). Subjects were recruited from universities in the Małopolska Region. Before taking part in the study all subjects gave their informed consent after being informed that the study is anonymous and participation is voluntary. They filled in paper-pencil questionnaires during their regular classes/ lectures in the presence of the researcher. No form of compensation was offered as an incentive to participate. The research was conducted in accordance with the Helsinki Declaration.

\section{Measures}

\section{The Excessive Internet Use Scale (EIUS)}

To measure problematic Internet use we utilized a questionnaire developed for the purpose of the study. It contains 12 questions about the frequency of behaviours related to excessive Internet use(see Table 1 for examples). The items are 
Table 1 Examples of items on the excessive internet use scale (translated from Polish)

\begin{tabular}{ll}
\hline No & Item \\
\hline 1 & How often do you think about the Internet (also when being "offline")? \\
2 & How often do you spend in the Internet more time than you intended? \\
8 & How often do you forget about your daily duties when surfing in the Internet? \\
12 & How often do you lie to your loved ones or someone else to hide your excessive Internet use? \\
\hline
\end{tabular}

based on the criteria of Internet addiction distinguished by Young (1998). Each item is measured on a 3-point Likert scale ranging from 1 (never) to 3 (often). Total score is computed by summing scores of all of the items. The scale showed satisfactory internal consistency (Cronbach's alpha for all items calculated in the current study: $\alpha=0.76$; item-total correlations ranging from: $r=0.32$ to $r=0.49$ ). Principal Component Analysisconducted on all of the scale's items revealed a one factor solution with item loading ranging from to 0.43 to 0.63 . Total score of the EIUS scale correlated significantly and positively with other self-reported measures of problematic Internet use such as: reported time (in hours) spent online $\left(\mathrm{r}_{\mathrm{s}}=0.21, p<0.001\right)$, frequency of visiting pornographic sites $\left(r_{s}=0.19, p<0.001\right)$ and frequency of surfing without purpose $\left(r_{\mathrm{s}}=0.41, \mathrm{p}<0.001\right)$.

\section{Self-Esteem Scale (SES)}

SES (Rosenberg, 1965) is a 10-item scale measuring self-esteem. Answers are given on a 4-point Likert scale with response options ranging from strongly agree (1) to strongly disagree (4). The higher the score the higher the self-esteem. The measure revealed good internal consistency with Cronbach's alpha calculated in the current study $\alpha=0.83$.

\section{UCLA Loneliness Scale (UCLA-III)}

Loneliness was measured by the 20-item UCLA loneliness scale (Russell, 1996a, Russell, 1996b). The Polish adaptation of the third version of the scale (Ochnik, 2016) was used. Response categories range from 1 (never) to 5 (always). Higher scores denote higher and more chronic loneliness. The scale has sound psychometric properties with Cronbach's $\alpha=0.88$ in the current study.

\section{Interpersonal Competence Questionnaire (ICQ)}

Interpersonal Competence Questionnaire (Buhrmester, Furman, Wittenberg, \& Reis, 1988), a 40-item self-report instrument measuring different aspects of interpersonal competence: 1 ) ability to initiate social interactions (Initiation -8 items); 2) ability to assert personal rights and express displeasure (Negative Assertion -8 items); 3) ability to disclose personal information (Disclosure - 8 items); 4) ability to provide emotional support to others (Emotional Support -8 items); 5) ability to manage interpersonal conflict (Conflict Management -8 items). The responses are given on a 5 point Likert scale ranging from 1 (poor at this) to 5 (extremely good at this). For each scale, the higher the score, the higher the interpersonal competence. The Polish version of the questionnaire was utilized (Ochnik, 2016). Only the subscale measuring the ability to initiate relationships was used in the analyses. In the present study, the Cronbach's alpha for Initiation subscale: $\alpha=0.88$.

\section{Results}

\section{Analytic strategy}

Before conducting main analyses correlation analyses were performed to examine the bivariate associations among the study variables. Hypotheses were tested using the PROCESS macro for SPSS (Hayes, 2017) which utilize ordinary least squares (OLS) regression approach to analysis of path models. This modelling tool uses the bootstrapping procedure to create confidence intervals (CI) for the indirect effects. The effect is deemed significant if the confidence interval does not cross zero. In the current analysis 5000 bootstrap resamples and $95 \%$ bias-corrected confidence intervals were used. Model number 6 (serial mediation analysis) was calculated which allowed for the testing of a specific theoretical sequence among factors mediating the relationship between the variables of interest.

Before the mediation analysis was conducted, the assumptions of linear multiple regression (no outliers, normal distribution of errors, no multicollinearity) were evaluated. There were about $2 \%$ data missing and they were dealt with listwise deletion. Sex and age were controlled for in the serial mediation model.

\section{Preliminary Analyses}

Descriptive statistics and results of the correlation analyses are presented in Table 2. 
Table 2 Descriptive statistics and results of correlational analysis (Spearman's rho)

\begin{tabular}{|c|c|c|c|c|c|c|c|c|c|}
\hline & $\begin{array}{l}\operatorname{Min} / \\
\operatorname{Max}\end{array}$ & $\mathrm{S}(\mathrm{SD})$ & $\mathrm{K}(\mathrm{SD})$ & $\mathrm{M}(\mathrm{SD})$ & (2) & (3) & (4) & $(5)$ & (6) \\
\hline SES (1) & $13 / 40$ & $-0.16(0.11)$ & $-0.01(0.22)$ & $24.41(5.06)$ & $0.49 * * *$ & $-0.52 * * *$ & $-0.18 * * *$ & 0.05 & $0.11 *$ \\
\hline Initiation ICQ (2) & $8 / 40$ & $-0.19(0.11)$ & $-0.40(0.22)$ & $24.67(6.57)$ & 1 & $-0.41 * * *$ & -0.05 & 0.06 & $0.16^{* * * *}$ \\
\hline UCLA-III (3) & $23 / 71$ & $0.26(0.11)$ & $-0.12(0.22)$ & $43.35(8.81)$ & & 1 & $0.23 * * *$ & -0.02 & 0.06 \\
\hline EIUS (4) & $12 / 32$ & $0.96(0.11)$ & $0.97(0.22)$ & $17.75(3.52)$ & & & 1 & -0.00 & $0.09^{*}$ \\
\hline Age (5) & $18 / 35$ & $6.27(0.11)$ & $67.59(0.22)$ & $19.89(1.32)$ & & & & 1 & $0.13 * *$ \\
\hline $\operatorname{sex}(6)$ & - & - & - & - & & & & & 1 \\
\hline
\end{tabular}

$N=508 ; * p<0.05 ; * * p<0.01 ; * * * p<0.001 ; \mathrm{S}$ - skewness; $\mathrm{K}$ - kurtosis; $\mathrm{M}$ - mean, SD - standard deviation, SES - total score of Self-Esteem Scale; Initiation ICQ - Initiation subscale of Interpersonal Competence Questionnaire; UCLA-III - total score of UCLA Loneliness Scale; EIUS - total score of Excessive Internet Use Scale

\section{The Serial Mediation Model}

The overall regression model predicting excessive Internet use from self-esteem, ability to initiate contacts and sense of loneliness was statistically significant $\left(\mathrm{R}^{2}=0.08, \mathrm{~F}[5483]=8.32\right.$, $p<0.001)$. Total relationship between self-esteem and excessive Internet use was negative and significant $(b=-0.12, \mathrm{SE}=$ 0.03 , CI: $-0.18,-0.06, p<0.001)$ meaning the lower selfesteem the more people engage in Internet activities. The link between self-esteem and the sense of loneliness was also negative and significant $(b=-0.82, \mathrm{SE}=0.07, \mathrm{CI}:-0.96,-0.67$, $p<0.001)$. Moreover, higher self-esteem was significantly associated with the better ability to initiate contact $(b=0.64, \mathrm{SE}=$ 0.05 , CI: $0.54,0.74, p<0.01$ ), which in turn was significantly linked with lower sense of loneliness $(b=-0.30, \mathrm{SE}=0.06$, CI: $-0.41,-0.18, p<0.001$ ) as well as with a higher tendency to excessive Internet use $(b=0.06, \mathrm{SE}=0.03, \mathrm{CI}$ : $0.01,0.12$, $p<0.05)$. Also, sense of loneliness significantly correlated with excessive Internet use ( $b=0.09, \mathrm{SE}=0.02$, CI: 0.05, 0.14. $p<$ $0.001)$. The indirect effects of ability to initiate social contacts as well as the indirect effect of loneliness on the association between self-esteem and excessive Internet use were statistically significant (mediation through ability to initiate contacts: $b=$ 0.04, SE $=0.02, \mathrm{CI}: 0.01,0.08$; mediation through sense of loneliness: $\mathrm{b}=-0.08, \mathrm{SE}=0.02, \mathrm{CI}=-0.12,-0.04$ ). Moreover, the sequential indirect effect of ability to initiate contact and loneliness on the link between self-esteem and excessive Internet use was statistically significant $(b=-0.02$, $\mathrm{SE}=0.01$, CI: $-0.03,-0,01)$. The direct effect of self-esteem on excessive InternetUse in serial mediation model was not significant $(\mathrm{b}=-0.07, \mathrm{SE}=0.04, \mathrm{CI}:-0.15,0.01, p=0.08)$ indicating full mediation (Fig. 1).

\section{Discussion}

The current study examined the relationships between selfesteem, the ability to initiate contacts, the sense of loneliness and excessive Internet use. The findings confirmed that low self-esteem is associated with excessive Internet use. Furthermore, the link between self-esteem and excessive Internet use is mediated by the ability to initiate contacts (people with lower self-esteem have lower ability to initiate contacts and use Internet more excessively) as well as by the sense of loneliness (individuals characterized by low self-esteem feel more lonely and higher loneliness is linked to excessive Internet use). Also, as hypothesised, the relationship between low self-esteem and excessive Internet use is sequentially mediated by the ability to initiate contacts and the sense of loneliness, suggesting, that the difficulty in initiating social interactions leading to the feeling of loneliness may explain the previously established link between low self-esteem and excessive Internet use.These results seems particularly important for excessive Internet use prevention and therapy.They suggest that implementing empirically supported interventions aimed at boosting self-esteem and reducing the sense of loneliness by increasing social competence, in particular the ability to initiate contact, can be helpful in efforts to lower excessive Internet use.

The scale of both problems - low social competence and excessive Internet use - is vast. Epidemiological studies indicate that with the development of Internet technology the risk of excessive Internet use increases. Poprawa (2011) demonstratedthat in a Polish sample of 3925 subjects aged between 11 and 65 just over $13 \%$ of young Internet users belong to the risk group of excessive Internet use. About 2\% score very high which may suggest that their Internet use is pathological (see Juczyński, Chodkiewicz and Pisarski 2004). Also, research shows that about $7-25 \%$ of the adult population is interpersonally incompetent (Spitzberg \& Cupach, 2002). The so-called social skills trainings work well in such cases, as individuals with difficulties learn adequate reactionsand proper functioning inspecific situations (Arygyle, 1994; Sofronoff, 2016). The results of the present study tentatively suggest that including the development of the ability to initiate contact in social skills trainings can offer 


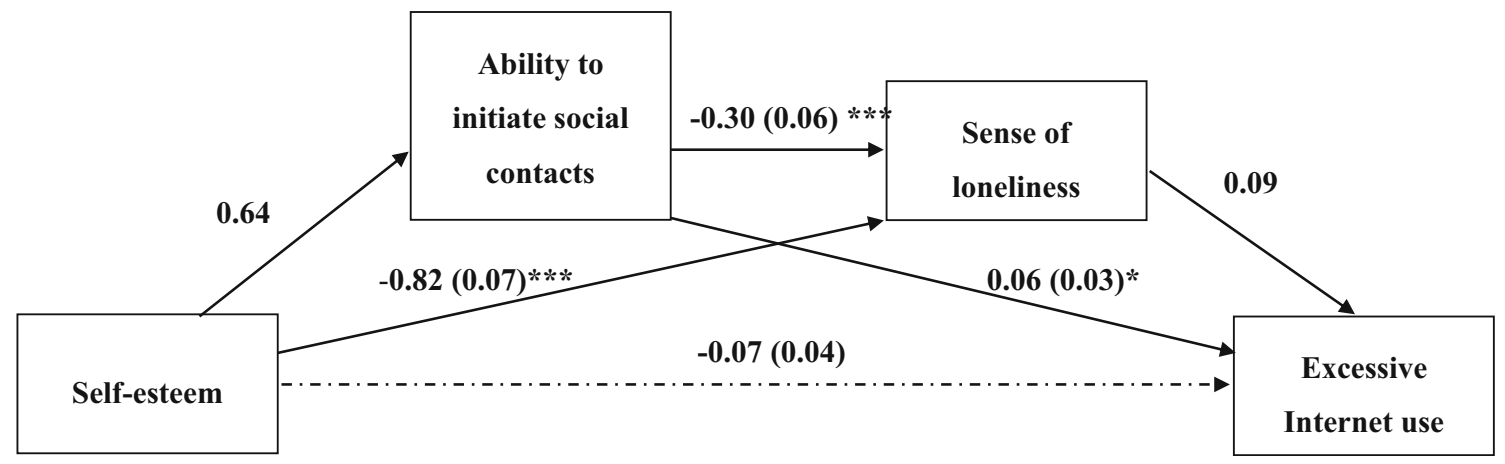

Fig. 1 Ability to initiate contacts and sense of loneliness sequentially mediating the association between self-esteem and excessive Internet use. Note: $* p<0.05, * * * p<0.001$; all path coefficients are unstandardized; SE values are given in brackets; sex and age were controlled for in the analysis; indirect effect of self-esteem through ability to initiate contacts: $b=0.04, \mathrm{SE}=0.02, \mathrm{CI}: 0.01,0.08$; indirect effect of self-esteem through feeling of loneliness: $\mathrm{b}=-0.08, \mathrm{SE}=0.02, \mathrm{CI}:-0.12,-0.04$; sequential indirect effect: $b=-0.02, \mathrm{SE}=0.01, \mathrm{CI}:-0.03,-0.01$ an additional educational and preventive effect - namely it can prevent excessive Internet use (see Thomas et al., 2019).

As has been demonstrated in the introduction, empirical evidence as well as existing theories support the links between low self-esteem and excessive Internet use (e.g., Widyanto \& Griffiths, 2019). Development of positive self-esteemhas been considered an important element of prevention programs for excessive usage of the Internet (Ma, Chu, \& Chan, 2011). Results of the current study provide further arguments that increasing personself- esteem could lead to decrease in excessive Internet use by improving his or her ability to initiate contact and thus reducing his or her sense of loneliness. However, as causality in psychopathology is often circular (Young 2015), a model of reciprocal causation should be considered.The directions of influence between the variables: self-esteem, sense of loneliness, social competence and excessive Internet use can be two-sided. Previous research showed thatimproved ability to initiate contact may boost self-esteem (see Cheng \& Furnham, 2002; Zhao et al., 2012; Zhou, Li, Tian, \& Huebner, 2018). Also,it has been postulated thats pending much time online may increase the level of social isolation (Chou, Condron and Belland, 2005; Kostak, Dindar, \& Dinçkol, 2018; Costa, Patrão, \& Machado, 2019) and diminishthe level of self-esteem (Craig, 1995). To draw definite conclusions about the direction of influence between analysed variables prospective or experimental studies are required, which we are planning to carry out. The results obtained in the study should be therefore treated as preliminary.However, regardless of the direction of influence, the sense of loneliness and social competence seem to be the variables which may be partially responsible for the previously studied link between low self-esteem and excessive Internet use.

The study has some other limitations that should be pointed out and taken into account when interpreting the results. Firstly, the present study was conducted in a non-clinical sample of university students and concerned excessive Internet use rather than Internet addiction. Therefore the conclusions drawn from this study cannot be generalized to clinical
populations.Moreover, we measured excessive Internet use with a questionnaire created for the purpose of the present study. Even though it proved to have good internal consistency we did not check its convergent validity with other existing measures of Internet addiction. Therefore,to a certain degree it may restrict the possibility of comparing the current findings with those derived from previous research using other measurements.

In spite of these limitations the current study provides important findings which may help to better understand the mechanisms of the association between low self-esteem and excessive Internet use. The results could be of interest to practitioners who specialize in addiction prevention as it tentatively suggests early interventions (targeting for example the inability to initiate contacts and sense of loneliness- partially related to this inability) that may be effective in case of individuals not yet addicted but using Internet excessively or those who do not yet present a problematic pattern of Internet use but seem to possess characteristics (e.g., low self-esteem) that make them vulnerable to develop such a pattern. It is especially important since the majority of intervention programs reported in the literature are tailored to those who already have problems and not to those at risk (Ke \& Wong, 2018).

Authors' Contributions $\mathrm{AD}$ and $\mathrm{DO}$ designed the study and collected the data, JK ran the statistical analysis, AD and JK wrote the first draft of the manuscript and interpreted the results. All authors approved the final version of the manuscript.

Data Availability The data will be available on request from the first author.

\section{Compliance with Ethical Standards}

Conflict of Interest Not applicable.

Ethics Approval All procedures performed in studies involving human participants were in accordance with the ethical standards of the institutional and/or national research committee and with the 1964 Helsinki declaration and its later amendments or comparable ethical standards. 
Consent to Participate All participants gave the written informed consent prior to the study.

Consent for Publication Neither the article nor portions of it have been previously published elsewhere. The manuscript is not under consideration for publication in another journal, and will not be submitted elsewhere until the Current Psychology editorial process is completed. All authors consent to the publication of the manuscript in Current Psychology, should the article be accepted by the Editor-in-chief upon completion of the refereeing process.

\section{Code Availability Not applicable.}

Open Access This article is licensed under a Creative Commons Attribution 4.0 International License, which permits use, sharing, adaptation, distribution and reproduction in any medium or format, as long as you give appropriate credit to the original author(s) and the source, provide a link to the Creative Commons licence, and indicate if changes were made. The images or other third party material in this article are included in the article's Creative Commons licence, unless indicated otherwise in a credit line to the material. If material is not included in the article's Creative Commons licence and your intended use is not permitted by statutory regulation or exceeds the permitted use, you will need to obtain permission directly from the copyright holder. To view a copy of this licence, visit http://creativecommons.org/licenses/by/4.0/.

\section{References}

Aouil B, Siedlaczek J. (2011). Osobowościowe determinanty dysfunkcjonalnego korzystania z Internetu wśród uczniów gimnazjum, liceum oraz studentów [Personal determinants of dysfunctional Internet usage among middle school, high school and university students] In: Aouil B, Czerwiński K, Wosik-Kawala D, eds. Internet wpsychologii, psychologia w Internecie [The Internet in psychology, psychology in the Internet]. Toruń: Adam Marszałek, Gnieźnieńska Szkoła Wyższa Milenium,101-235.

Armstrong, L., Phillips, J. G., \& Saling, L. L. (2000). Potential determinants of heavier internet usage. International Journal of Human Computer Studies, 53, 537-550.

Arygyle, M. (1994). The Psychology of Interpersonal Behaviour. Penguin Adult

Buhrmester, D., Furman, W., Wittenberg, M. T., \& Reis, H. T. (1988). Five domains of interpersonal competence in peer relationships. Journal of Personality and Social Psychology, 55, 991-1008.

Caplan, S. E. (2002). Problematic internet use and psychosocial wellbeing: Development of a theory-based cognitive-behavioral measurement instrument. Computers in Human Behavior, 18, 553-575.

Caplan, S. E. (2003). Preference for online social interaction: A theory of problematic internet use and psychosocial well-being. Communication Research, 30, 625-648.

Caplan, S. E. (2006). A social skill account of problematic internet use. Journal of Communication, 55(4), 721-736.

Casale, S., \& Fioravanti, G. (2011). Psychosocial correlates of internet use among Italian students. International Journal of Psychology, 46(4), 288-98.

Cheng, H., \& Furnham, A. (2002). Personality, peer relations, and selfconfidence as predictors of happiness and loneliness. Journal of Adolescence, 25, 3, 327-339.

Chou, Ch., Condron, L., \& Belland, J. (2005). A review of the research on internet addiction. Educational Psychology Review, 17, 363-388.
Coplan RJ, Bowker JC. (2014). The Handbook of Solitude: Psychological Perspectives on Social Isolation, Social Withdrawal, and Being Alone. Wiley-Blackwell, p 608

Costa, R. M., Patrão, I., \& Machado, M. (2019). Problematic internet use and feelings of loneliness. International Journal of Psychiatry in Clinical Practice, 23(2), 160-162.

Craig, R. J. (1995). The role of personality in understanding substance abuse. Alcoholism Treatment Quarterly, 13(1), 17-27.

Dembińska, A., \& Ochnik, D. (2014). Use of Internet and its Addictive risk among Polish students - comparative analysis over a seven-year period. Polish Journal of Applied Psychology, 12(4), 53-68.

Dembinska, A., \& Ochnik, D. (2014). Internet Addiction and Relationships with Insomnia. A Cross-Sectional Designed Study: Anxiety, Depression, Stress and Self-Esteem in University Students.

Durkee, T., Kaess, M., Carli, V., Parzer, P., Wasserman, C., \& Floderus, B. (2012). Prevalence of pathological internet use among adolescents in Europe: demographic and social factors. Addiction, 107(12), 2210-22.

Fioravanti, G., Dèttore, D., \& Casale, S. (2012). Adolescent Internet addiction: testing the association between self-esteem, the perception of Internet attributes, and preference for online social interactions. Cyberpsychology, Behavior, and Social Networking, 15(6), 318-23.

Goldberg I. (1996) Internet Addictive Disorder (IAD). Diagnostic criteria. www.psycom.net/iadcriteria.html.

Griffiths, M. (2000). Does internet and computer "addiction" exist? Some case study evidence. Cyberpsychology\&behavior, 2(3), 217.

Griffiths, M. (2005). A 'components' model of addiction within a biopsychosocial framework. Journal of Substance Use, 10(4), 191-197.

Hayes, A. F. (2017). Introduction to mediation, moderation, and conditional process analysis: A regression-based approach. New York, US: Guilford Publications.

Juczynski, Z., Chodkiewicz, J., \& Pisarski, A. (2004). Zachowania ryzykowne i szkodliwe dla zdrowia dzieci i młodzieży. Łodzi, Miejski Ośrodek Profilaktyki i Terapii Uzależnień: Monitorowanie zachowań zdrowotnych uczniów m.

Ke, G. N., \& Wong, S. F. (2018). A healthy mind for problematic internet use. Cyberpsychology, Behavior and Social Networking, 21, 10 645. https://doi.org/10.1089/cyber.2018.0072.

Kim, H. H., \& Davis, K. E. (2009). Toward a comprehensive theory of problematic internet use: Evaluating the role of self-esteem, anxiety, flow, and the self-rated importance of internet activities. Computers in Human Behavior, 25, 490-500.

Kim, J., \& Haridakis, P. M. (2009). The role of internet user characteristics and motives in explaining three dimensions of internet addiction. Journal of Computer-Mediated Communication, 14(4), 9881015.

Kittinger, R., Correia, C. J., \& Irons, J. G. (2012). Relationship between Facebook use and problematic Internet use among college students. Cyberpsychology, Behavior, and Social Networking, 15(6), 324-7.

Kormas, G., Critselis, E., Janikian, M., Kafetzis, D., \& Tsitsika, A. (2011). Risk factors and psychosocial characteristics of potential problematic and problematic internet use among adolescents: a cross-sectional study. BMC Public Health, 11, 595.

Kostak, M. A., Dindar, I., \& Dinçkol, R. Z. (2018). Loneliness, depression, social support levels, and other factors involving the internet use of high school students in Turkey. International Journal of Mental Health and Addiction., 14(71), 1-14.

Lee, Z.W.-Y., Cheung, Ch., \& Mei-Kwan,. (2014). Problematic use of social networking sites: The role of self-esteem. International Journal of Business and Information, 9(2), 143-159.

Ma, H. K., Chu, M. K., \& Chan, W. W. (2011). Construction of a teaching package on promoting prosocial internet use and preventing antisocial internet use. The Scientific World Journal, 11, 21362146. 
McKenna, K. Y. A., \& Bargh, J. A. (2000). Plan 9 from cyberspace: The implication of the internet for personality and social psychology. Personality and Social Psychology Review, 4, 57-75.

Niemz, K., Griffiths, M., \& Banyard, P. (2005). Prevalence of Pathological Internet Use among University Students and Correlations with Self-Esteem, the General Health Questionnaire (GHQ), and Disinhibition. Cyber Psychology \& Behavior, 8, 562 570

Nowland, R., Necka, E. A., \& Cacioppo, J. T. (2018). Loneliness and Social Internet Use: Pathways to Reconnection in a Digital World? Perspectives on Psychological Science, 13(1), 70-87. https://doi. org/10.1177/1745691617713052.

Ochnik, D. (2016). Singlehood - psychosocial consequences of being single in men and women. Ph.D. diss., Dept. of Psychology, University of Silesia. Retrieved from http://www.sbc.org.pl/publication $/ 246942$

Panayiotou, G., Pantelia, M., \& Theodorou, M. (2016). Predictors of loneliness in a sample of college men and women in Cyprus: The role of anxiety and social skills. Psychology, Community \& Health, $5(1), 16-30$.

Pontes, H. M., Kuss, D. J., \& Griffiths, M. D. (2015). Clinical psychology of internet addiction: A review of its conceptualization, prevalence, neuronal processes, and implications for treatment. Neuroscience and Neuroeconomics, 4, 11-23.

Poprawa R. (2011). Test problematycznego użytkowania internetu young. Adaptacja i ocena psychometryczna internet addiction test young [Test of Problematic Using Inernet. Polish Adaptation and validation of K. Young's Internet Addiction Test. Przegląd Psychologiczny. 54 (2): 193-216

Riggio, R. E., \& Steven De Paola, B. T. (1990). Social skills and selfesteem. Personality and Individual Differences., 11(8), 799-804.

Rosenberg, M. (1965). Society and the adolescent self-image. Princeton, New Jersey: Princeton University Press.

Russell, D. (1996a). UCLA loneliness scale (version 3): Reliability, validity, and factor structure. Journal of Personality Assessment, 66(1), 20-40.

Russell, D. W. (1996b). UCLA loneliness scale (version 3): Reliability, validity, and factor structure. Journal of Personality Assessment, 66(1), 20-40

Smahel, D., Brown, B. B., \& Blinka, L. (2012). Associations between online friendship and Internet addiction among adolescents and emerging adults. Developmental Psychology, 48(2), 381-8.

Sofronoff K. (2016). Social skills training approaches for children and youth: Theory, research, and practice. Journal of American Academy of Child and Adolescent Psychiatry. 55, 10, supplement, 49.
Solano, C. H., \& Koester, N. H. (1989). Loneliness and communication problems: Subjective anxiety or objective skills? Personality and Social Psychology Bulletin, 15, 126-133. https://doi.org/10.1177/ 0146167289151012.

Spitzberg, B.H. \& Cupach, W.R. (2002). Interpersonal skills. In M.L. Knapp \& J.R. Daly (Eds.), Hanbook of interpersonal communication. $3^{\text {rd }}$ ed., pp.564-611. Newbury Park, CA: Sage.

Stieger, S., \& Burger, C. (2010). Implicit and explicit self-esteem in the context of internet addiction. Cyberpsychology, Behavior, and Social Networking, 13(6), 681-8.

Thomas W.H., Chung M.H.A., Simmy M.Y., Sum M., Monique W.L., Chan M. (2019). Adolescent internet addiction in Hong Kong: Prevalence, psychosocial correlates, and prevention. Journal of Adolescent Health, 64, 6, Supplement, S34-S43.

Wartberg, L., Sack, P. M., Petersen, K. U., \& Thomasius, R. (2011). Psychopathology and achievement motivation in adolescents with pathological internet use. Prax Kinderpsychol Kinderpsychiatr., 60(9), 719-34.

Widyanto, L.,Griffiths, M.D. (2019). An Empirical Study of Problematic Internet Use and Self-Esteem. [in] Internet and Technology Addiction: Breakthroughs in Research and Practice. Pages: 14.

Yao, M. Z., \& Zhong, Z.-J. (2014). Loneliness, social contacts and Internet addiction: A cross-lagged panel study. Computers in Human Behavior, 30, 164.

Younes F, Halawi G, Jabbour H, El Osta N, Karam L, Hajj A, Rabbaa Khabbaz LR. (2016). Internet Addiction and Relationships with Insomnia, Anxiety, Depression, Stress and Self-Esteem in University Students: A Cross-Sectional Designed Study. PLoS One. 12;11(9):e0161126.

Young, K. S. (1996). Internet Addiction: The emergence of a new clinical disorder. CyberPsychology \& Behavior, 1, 237-244.

Young, K. S. (1998). Internet addiction: The emergence of a new clinical disorder. Cyberpsychology\&behavior, 1(3), 237-244.

Zhao, J., Kong, F., \& Wang, Y. (2012). Self-esteem and humor style as mediators of the effects of shyness on loneliness among Chinese college students. Personality and Individual Differences, 52, 686690. https://doi.org/10.1016/j.paid.2011.12.024.

Zhou, J., Li, X., Tian, L., Huebner, E.S. (2018). Longitudinal association between low self-esteem and depression in early adolescents: The role of rejection sensitivity and loneliness. Psychology and Psychotherapy. Theory, Research and Pratcice https://doi.org/10. 1111/papt.12207.

Publisher's Note Springer Nature remains neutral with regard to jurisdictional claims in published maps and institutional affiliations. 